\title{
Robotic thoracic esophagectomy with radical lymphadenectomy: A preliminary study
}

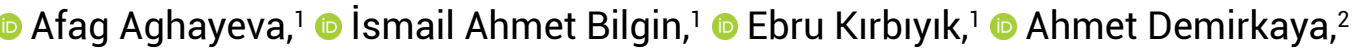

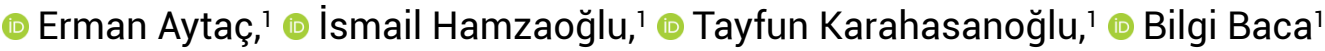 \\ 'Department of General Surgery, Acibadem Mehmet Ali Aydinlar University Faculty of Medicine, İstanbul, Turkey \\ ${ }^{2}$ Department of Thoracic Surgery, Acibadem Mehmet Ali Aydinlar University Faculty of Medicine, İstanbul, Turkey
}

\begin{abstract}
Introduction: Esophagectomy with the maximal number of harvested lymph nodes remains the mainstay for esophagus cancer (EC) treatment. The present study aims to evaluate the short and long-term outcomes of patients with $\mathrm{EC}$ who underwent robotic esophagectomy (RE) with thoracic radical lymphadenectomy.

Materials and Methods: Between April 2015 and April 2018, consecutive patients who underwent RE were retrieved from a prospectively maintained registry. Patient demographics, operative variables and postoperative outcomes were assessed.

Results: In this study, there were 22 ( 10 females) patients (mean age was $60.3 \pm 8.9$ years). The mean operative time and estimated blood loss was $456 \pm 71.85$ minutes and $213 \pm 157 \mathrm{~mL}$, respectively. The mean number of harvested lymph nodes was $24.5 \pm 9$. 96 . The overall 30 -day complication rate was $36 \%(n=8)$. OS was calculated as $87 \%$ during 25.6 (range, 12-51) months of mean follow-up time.

Conclusion: According to our limited number of patients, robotic technology was safe and feasible in esophageal cancer surgery. Comparative studies with the robotic approach are needed.
\end{abstract}

Keywords: Esophageal cancer; esophagectomy; Ivor Lewis; lymphadenectomy; robot.

\section{Introduction}

Esophagectomy is the primary treatment for esophageal cancer. ${ }^{[1]}$ With con-troversies remaining between the conventional open technique and minimal invasive technique. Conventional open esophagectomy (OE) is an invasive surgical procedure with high morbidity and mortality rates. ${ }^{[2]}$ OE has 5-10\% perioperative mortality and 30-40\% morbidity rates. ${ }^{[3]}$ Minimal invasive esophagectomy (MIE) has superiority in decreasing the 30-day mortality and morbidity over OE. ${ }^{[4,5]}$ Studies about MIE re-ported better recovery period, less postoperative pain and less cardiopulmonary compli-cation rates. ${ }^{[6-9]}$ Some technical limitations of laparoscopic approach led to the devel-opment of the robotic platform. Rigid instruments with limited range of motion, unsta-ble retraction and assistant-dependent visualization is overcome by the robotic platform. There were some publications about the initial effectiveness and safety of the RE with short-term outcomes. ${ }^{[10-12]}$

The therapeutic value of high number of harvested lymph 
nodes was demonstrat-ed as significant for overall survival after esophagectomy. ${ }^{[13]}$ It is more difficult to make extended lymphadenectomy thoracoscopically because of the location of vital structures in the mediastinum. However, technical advantages of the robotic platform can ease a careful and safe lymphatic dissection in the mediastinum. It could be assumed that with the help of polyarticular fine maneuver of the robotic platform there could be less recurrent laryngeal nerve palsy.

The aim of this article was to evaluate the short and longterm outcomes of the patients with esophageal cancer who underwent RE with thoracic radical lymphadenectomy and clarify the details of our technique.

\section{Materials and Methods}

\section{Patients}

After obtaining the approval from the Institutional Review Board (Decision No: 2020-01/42), medical records of 22 patients undergoing RE between April 2015 and April 2018 were reviewed retrospectively from a prospective registry. Data was ob-tained from research electronic data capture (REDCap) program. Inclusion criteria were age ranging from 18 to 75 years, patients with resectable and non-metastatic esophageal cancer and patients with histologically verified malignancy. All patients signed the informed consent.

Data were evaluated relative to demographics, perioperative parameters (opera-tive time, estimated blood loss, conversion rate), postoperative short-term (postoperative 30-day complications, length of hospital stay, harvested number of lymph nodes, R0 resection rate, mortality rate) and long-term outcomes (long-term complications, overall survival, disease free survival) were retrieved. Postoperative 30-day complications in-cluded cardiopulmonary complications, venous thromboembolism, sepsis, surgical site infections, anastomotic leak and bleeding. Overall survival time was calculated from the date of operation until the date of death.

For preoperative work-up: endoscopic biopsy, endoscopic ultrasonography to evaluate local invasion and lymph node involvement, and to determine stage contrast-enhanced computed tomography scan was performed. T3/ $\mathrm{T} 4$ and any $\mathrm{N}$ positive patient underwent neoadjuvant chemoradiotherapy (NCCN Guidelines Version 2.2019). Fol-low-up was performed every 3-6 mo for 1-2 y, every 6-12 mo for 3-5 y, then annually.

\section{Operative technique}

Thoracic phase of the operation was performed robotically and the abdominal part was open/robotic. Patient was placed in left lateral decubitus position for thoracic phase. For the procedure, three $8 \mathrm{~mm}$ robotic trocars and one $5 \mathrm{~mm}$ assistant trocar for bedside surgeon were used (Fig. 1). Later, the 5-mm assistant trocar was changed with a 12-mm robotic trocar. Single docking was done. The robot (da Vinci Xi, Intuitive Surgical Inc, Sunnyvale, CA) was set from the patient's right. The dissection routinely starts with identification of the Azygos vein (Fig. 2) and transection of it with an en-doscopic vascular stapler. The esophagus was mobilized together with periesophageal lymph nodes. Esophagus is liberated off the aorta (Fig. 3). Care should be taken not to damage the recurrent laryngeal nerve (RLN) during dissection of the superior part of the esophagus (Fig. 4). Generally, lymph nodes around RLNs are removed en-bloc with the esophagus.

For the abdominal phase, either robotic or open approach was used. After the mobilization of stomach, a gastric conduit was constructed with a linear stapler, then pulled

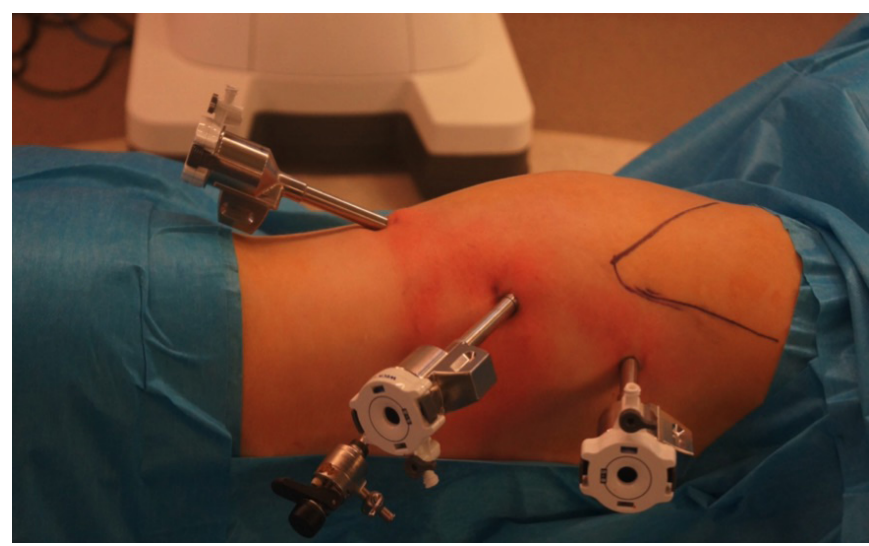

Figure 1. Trocar positions.

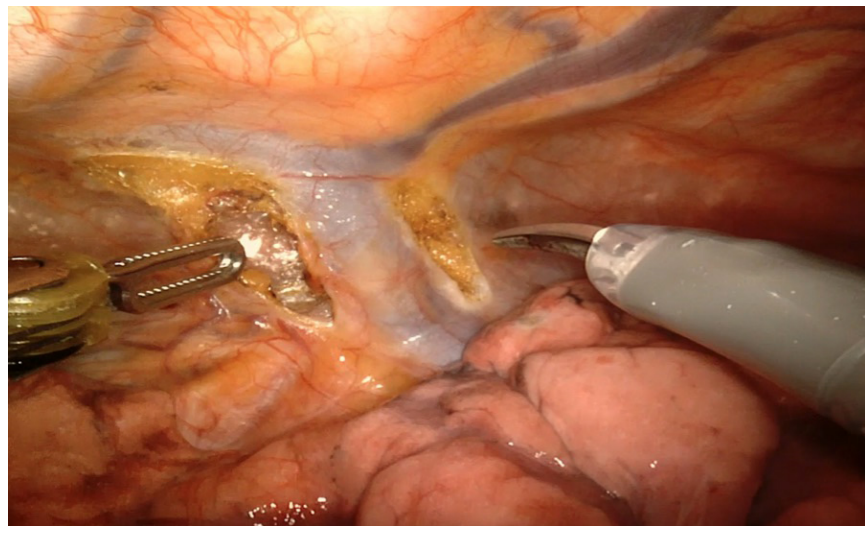

Figure 2. Appearance of the Azygos vein. 


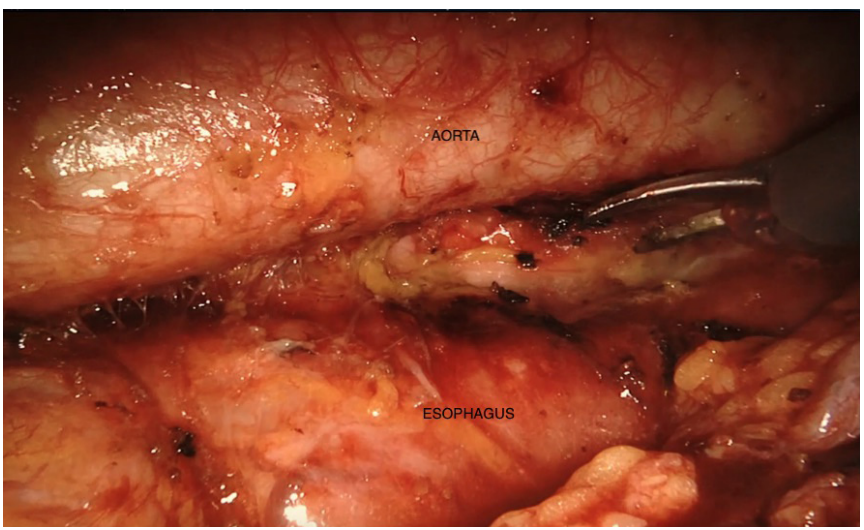

Figure 3. Appearance of the aorta during paraesophageal lymph node dissection.

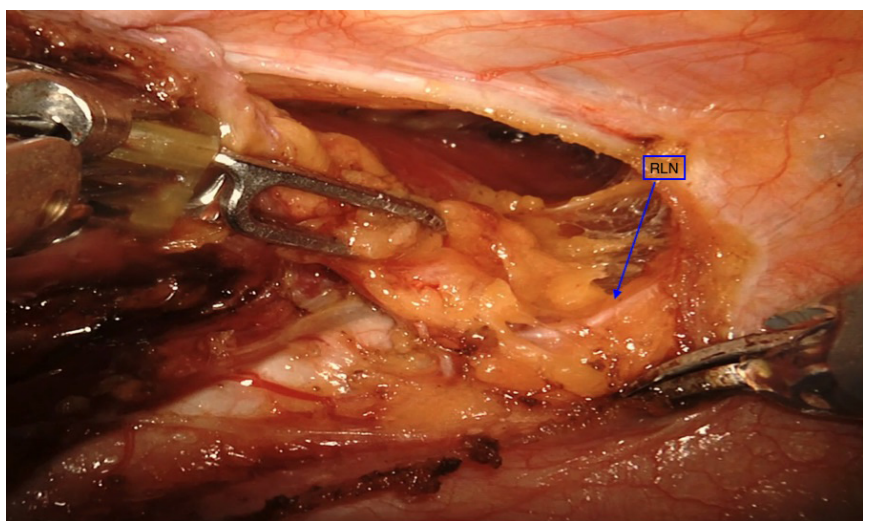

Figure 4. Appearance of the recurrent laryngeal nerve.

up to the cervical region through the mediastinum and gastroesophage-al/gastropharyngeal anastomosis was performed with 3/0 Vicryl suture.

If the tumor was located at the distal part of the esophagus, then Ivor Lewis pro-cedure was performed. For Ivor Lewis procedure, both abdominal and thoracic phases were performed robotically. The operation was started with the abdominal phase. Gas-tric conduit was constructed with a stapler at the level of incisura angularis and pyloro-plasty was performed. After the completion of abdominal phase, position of the patient was changed into the left lateral decubitus position for the thoracic phase. Port positions were the same with the total esophagectomy procedure. The azygos vein was not ligated in this procedure. Paratracheal, paraesophageal, subcarinal and celiac lymphadenectomy were performed. Transection of the esophagus at the level of azygos vein was per-formed with a robotic stapler and intracorporeal esophagogastric anastomosis was per-formed. The specimen was extracted within an endo-bag via enlargement of the 12-mm robotic trocar site.

\section{Results}

A total of 22 patients with esophageal cancer underwent RE during the study period. Patient demographics and clinical characteristics are delivered on Table 1 . The mean age of patients was $60.3 \pm 8.9$ years and of the 22 patients, there were 12 male and 10 females with a mean BMI of $26.5 \pm 6.64 \mathrm{~kg} / \mathrm{m}^{2}$. Previous thoraco-abdominal opera-tion rate was $13 \%(\mathrm{n}=3)$ (one laparoscopic cholecystectomy and two thoracotomy for benign pulmonary diseases). Fifteen patients underwent neoadjuvant chemoradiothera-py for locally advanced esophageal cancer.

Operative outcomes and postoperative findings were provided in Table 2. Elev-en out of 22 patients underwent totally robotic procedure (thoracic and abdominal stages were performed robotically). Of them, three patients underwent Iwor Levis and 19 pa-tients underwent total esophagectomy and gastric pull-up procedures. Estimated blood loss (EBL) was $213 \pm 157 \mathrm{~mL}$. There were no perioperative complications. There was no conversion. The overall 30-day complication rate was $36 \%(\mathrm{n}=8)$. Anastomotic leakage rate was $13.6 \%(n=3)$ and all anastomotic leakages were managed conservatively. There was vocal cord paralysis in one patient. There was one chylothorax and was managed by Lipiodol ${ }^{\circledR}$ Ultra Fluid embolization of the ductus thoracicus.

Table 1. Patient demographics and clinical characteristics

$\begin{array}{lc}\text { Age, years, mean } \pm \text { SD } & 60.3 \pm 8.9 \\ \text { Gender, } \mathrm{n}(\%) & \\ \quad \text { Female } & 10(45) \\ \quad \text { Male } & 12(55) \\ \text { BMI, kg/m }{ }^{2} \text {, mean } \pm S D & 26.5 \pm 6.64 \\ \text { ASA score, } \mathrm{n}(\%) & \\ \quad \text { ASA I } & 18(82) \\ \text { ASA II } & 4(18) \\ \text { History of smoking, } \mathrm{n}(\%) & 1(5) \\ \quad \text { Yes } & 21(95) \\ \quad \text { No } & 3(13) \\ \text { Previous thoracoabdominal surgery, } \mathrm{n}(\%) & \\ \text { Tumor location, } \mathrm{n}(\%) & 4(18) \\ \quad \text { Middle thoracic } & 18(82) \\ \quad \text { Lower thoracic } & 15(68) \\ \text { Neoadjuvant therapy, } \mathrm{n}(\%) & \end{array}$

Continuous variables are described as mean \pm standard deviation, categorical variables are described as $\mathrm{n}(\%)$. 
Histopathological results were given in Table 2. R0 resection was achieved in all patients. Mean number of harvested lymph nodes was $24.5 \pm 9.96$. The mean number of metastatic lymph nodes was $0.95 \pm 1.61$. Final pathology of six patients revealed T3N1-2 adenocarcinoma and these patients underwent adjuvant chemotherapy and the rest were followed without any additional treatment.

Mean follow-up time was $25.6 \pm 13.07$ months and during this period there were three mortalities, one recurrence in the abdominal lymph nodes and two distant multiple metastases in the liver and lung, respectively. One year overall survival (OS) and dis-ease free survival (DFS) rate was $91 \%(\mathrm{n}=20)$. OS was calculated as $87 \%$ during 25.6 (range, 12-51) months of mean follow-up time.

\section{Table 2. Operative outcomes}

Operative time, minutes, mean $\pm S D$

$456 \pm 71.85$

Estimated blood loss, $\mathrm{mL}$, mean $\pm \mathrm{SD}$

$213 \pm 157$

Conversion, $\mathrm{n}(\%)$

$0(0)$

Postoperative complications, $\mathrm{n}(\%)$

Anastomotic leak

Vocal cord paralysis

1 (4)

Pneumonia

Atelectasis

Pleural effusion

1 (4)

Chylothorax

$1(4)$

Tumor size, $\mathrm{pT}$ stage

TO

T1

$\mathrm{T} 2$

2 (9)

T3

8 (36)

pN stage, $n(\%)$

NO

N1

N2

Pathology, n (\%)

Adenocarcinoma

Squamous cell carcinoma

Number of harvested lymph

nodes, mean $\pm S D$

Length of hospital stay, days, mean $\pm S D$

$12 \pm 9.94$

Length of ICU stay, days, mean \pm SD

Continuous variables are described as mean \pm standard deviation, categorical variables are described as n (\%); ICU: intensive care unit.

\section{Discussion}

According to the results of this study, it was seen that with the help of the ro-botic technology esophagectomy can achieve good oncologic resections and acceptable longterm outcomes.

MIE is not routinely performed worldwide due to a steep learning curve and high technical complexity. In one meta-analysis, it was reported that there were no sta-tistically significant differences between MIE and RE regarding R0 resection rate, some complications, mortality rate, operative time, hospital stay, and harvested lymph nodes. However, in the same study, it was seen that intraoperative blood loss and vocal cord palsy rate was less in RE when compared to MIE. ${ }^{[14]}$ Theoretically, robotic surgery with its enhanced dexterity and increased range of motion facilitates meticulous dissec-tion and thus may accelerate the learning curve. What we learned from rectal surgery is that, the robotic platform had a superiority over laparoscopy in performing precise dis-section in narrow spaces. Since the mediastinum also has a limited space, then it could be proposed that the robotic platform could also have some advantages in this area.

In our study, median operative time was 450 minutes and this was comparable to the literature with median operative times between 335-490 minutes. ${ }^{[11,15-17]}$ Weksler et al. ${ }^{[11]}$ and Suda et al. ${ }^{[16]}$ reported that the operative time of MIE was longer when compared to the RE because of faster thoracic mobilization. Short-term postoperative outcomes of MIE and RE were found superior than open procedures with decreasing 30-day mortality-morbidity, lower postoperative pain, better short-term qual-ity of life and better short-term postoperative functional recovery. ${ }^{[4,18]}$

Mean estimated blood loss in this study was $213 \pm 157 \mathrm{~mL}$, concordant with the amounts reported in the literature as 92-462 $\mathrm{mL}$ and 102-466 mL for RE and MIE, re-spectively. ${ }^{[14]}$

In a population-based study from the Netherlands that included 2698 patients, reported that high harvested lymph nodes (at least 15) were associated with higher overall survival in patients with esophageal cancer. ${ }^{[13]}$ In our study, mean harvested number of lymph nodes was $24.5 \pm 9.96$ and it was comparable with the literature. The ROBOT trial showed that robotic surgery was comparable to open surgery in retrieval of adequate amount of lymph nodes. ${ }^{[18]}$ Similarly, other studies also confirmed these results. ${ }^{[4,19,20]}$ On the other hand, some studies reported higher number of harvested lymph nodes during MIE compared to OE..$^{[21,22]}$ 
Routinely, performing paratracheal lymphadenectomy is still under debate and is considered to be technically challenging during esophagectomy. Because of the location of nearby vital structures like superior vena cava, membranous part of the trachea and RLN in paratracheal region, many surgeons fear to damage these structures, so perform paratracheal lymph node dissection for patients with proximal or mid-esophageal can-cers. However, in a recent study it was found that dissection of paratracheal lymph nodes in a patient with mid-to distal esophageal tumors has a high therapeutic im-portance in terms of longterm survival. ${ }^{[23]}$ To overcome the disadvantages of laparoscopic transhiatal esophagectomy in upper mediastinal lymphadenectomy Fujiwara et al, developed single-port mediastinoscopic transcervical technique. ${ }^{[24,25]}$ However, in the same study vocal cord palsy rate was more frequent (33\%). Lymphadenectomy around the RNL needs innovative dexterities to avoid the nerve palsy, which results as pneumonia. Technical advantages of robotic platform can provide a careful and safe dis-section in this dangerous anatomical area. There are studies reporting that achieving a higher number of dissected lymph nodes along RLN were significant in robotic group than laparoscopy. ${ }^{[12,15,1,26]}$ Our team generally makes en-bloc esophagectomy with lymphadenectomy (with paratracheal lymph nodes) regardless of the location of the tu-mor (distal, middle or upper).

Oncologic outcomes of our study include R0 resection rate, harvested lymph node number, disease free and overall survival. In Wullstein et al.'s ${ }^{[27]}$ study, R0 resection rate was found as $92 \%$ in MIE and $84 \%$ in OE. It was shown that RE could facili-tate the resection of cT4b tumors after down-staging by chemoradiotherapy. ${ }^{[28]}$ Radiotherapy may lead to a severe fibrosis between esophagus and the surrounding structures and this may cause a challenging dissection. Nevertheless, with the help of robotic plat-form , precise exploration of the anatomical planes were achieved and this could help in avoiding damages to the vital structures while preserving the surgical margins.

Postoperative complication rates (anastomotic leak, pneumonia, chylothorax, empyema, and arrhythmia) were not observed as statistically significant between RE and MIE. ${ }^{[14]}$ It was demonstrated that pulmonary complications were lower in MIE than OE. ${ }^{[5,29-32]}$ However, there was no statistically significant difference regarding the anastomotic leak rate between MIE and OE. ${ }^{[5,29,31,32]}$ On the other hand, there was no statistically significant differ- ence between MIE and RE regarding postoperative early complication rates other than vocal cord palsy. ${ }^{[14]}$ Vocal cord palsy incidence was higher in MIE than RE. ${ }^{[14]}$ The most potentially lethal complication during the postoperative period is anastomotic leakage and can range from 0 to $19 \%$ in MIE and is comparable with OE. ${ }^{[20,33-35]}$ In our study, anastomotic leakage rate was $13.6 \%(n=3)$ and this finding was in line with literature. In a propensitymatched analysis, anastomotic leakage was diagnosed in $12 \%$ of RE and $18 \%$ of MIE. ${ }^{[36]}$

In our study, median follow-up time was 23.5 (range, 1251) months, and one-year and three-year OS rates were $91 \%(n=20)$ and $86 \%(n=6)$, respectively. Park et al., ${ }^{[37]}$ analyzed the long-term survival and demonstrated that the 5-year OS difference was not statistically significant between RE and MIE. Osugi et al., ${ }^{[19]}$ reported comparable 3-year survival rates between hybrid MIE and OE.

The present study has some limitations, most of which arise from the nature of the retrospective study, non-comparative design, and small sample size. However, the high case experience, our strict selection criteria and presence of the long-term outcomes strengthen its clinical value.

\section{Conclusion}

According to our limited sample size of experience, robotic technology was safe and feasible in esophageal cancer surgery. Besides, robotic approach provided oncologically comparable specimens with a high number of harvested lymph nodes and improved survival. Further comparative studies are needed.

\section{Disclosures}

Ethichs Committee Approval: The Ethics Committee of Acibadem Mehmet Ali Aydinlar University provided the ethics committee approval for this study (09.01.20202020-01/42).

Peer-review: Externally peer-reviewed.

Conflict of Interest: None declared.

Authorship Contributions: Concept - B.B., I.H., A.A.; Design - E.K., I.A.B., E.A.; Supervision - A.D., I.A.B., T.K.; Materials - A.A., I.A.B.; Data collection and/or processing - A.A., I.H., T.K.; Analysis and/ or interpretation - E.K., A.A., E.A.; Literature search - A.A., B.B., E.A.; Writing A.D., E.K., A.A., E.A.; Critical review - A.D., B.B., I.H., A.A. 


\section{References}

1. Torre LA, Bray F, Siegel RL, Ferlay J, Lortet-Tieulent J, Jemal A. Global cancer statistics, 2012. CA Cancer J Clin 2015;65:87108. [CrossRef]

2. DeSantis $C E$, Lin CC, Mariotto AB, Rebecca L Siegel, Kevin D Stein, Joan L Kramer, et al. Cancer treatment and survivorship statistics, 2014. CA Cancer J Clin 2014;64:25271.

3. Wu PC, Posner MC. The role of surgery in the management of oesophageal cancer. Lancet Oncol 2003;4:4818. [CrossRef]

4. Biere SSAY, van Berge Henegouwen MI, Maas KW, Bonavina L, Rosman C, Garcia RJ et al. Minimally invasive versus open oesophagectomy for patients with oesophageal cancer: a multicentre, open-label, randomised controlled trial. Lancet 2012;379:1887-92. [CrossRef]

5. Yibulayin W, Abulizi S, Lv H, Sun W. Minimally invasive oesophagectomy versus open esophagectomy for resectable esophageal cancer: a meta-analysis. World J Surg Oncol 2016;14:304. [CrossRef]

6. Luketich JD, Pennathur A, Awais O, Levy RM, Keeley S, Shende $M$, et al. Outcomes after minimally invasive esophagectomy: review of over 1000 patients. Ann Surg 2012;256:95103.

7. Levy RM, Pennathur A, Luketich JD. Randomized trial comparing minimally invasive esophagectomy and open esophagectomy: early perioperative outcomes appear improved with a minimally invasive approach. Semin Thorac Cardiovasc Surg 2012;24:1534. [CrossRef]

8. Levy RM, Trivedi D, Luketich JD. Minimally invasive esophagectomy. Surg Clin North Am 2012;92:126585. [CrossRef]

9. Mallipeddi $\mathrm{MK}$, Onaitis MW. The contemporary role of minimally invasive esophagectomy in esophageal cancer. Curr Oncol Rep 2014;16:374. [CrossRef]

10. Espinoza-Mercado F, Imai TA, Borgella JD, et al. Does the approach matter? comparing survival in robotic, minimally invasive, and open esophagectomies. Ann Thorac Surg 2019;107:378-85. [CrossRef]

11. Weksler B, Sharma P, Moudgill N, Chojnacki KA, Rosato EL. Robot-assisted minimally invasive esophagectomy is equivalent to thoracoscopic minimally invasive esophagectomy. Dis Esophagus 2012;25:403-9. [CrossRef]

12. Deng HY, Huang WX, Li G, Li SX, Luo J, Alai G, et al. Comparison of short-term outcomes between robot-assisted minimally invasive esophagectomy and video-assisted minimally invasive esophagectomy in treating middle thoracic esophageal cancer. Dis Esophagus 2018;31. [CrossRef]

13. Visser E, van Rossum PSN, Ruurda JP, van Hillegersberg R. Impact of Lymph Node Yield on Overall Survival in Patients Treated With Neoadjuvant Chemoradiotherapy Followed by Esophagectomy for Cancer: A Population-based Cohort Study in the Netherlands. Ann Surg 2017;266:863-9. [CrossRef]

14. Jin D, Yao L, Yu J, Liu R, Guo T, Yang K, et al. Robotic-assisted minimally invasive esophagectomy versus the conventional minimally invasive one: A meta-analysis and systematic review. Int J Med Robot 2019;15:e1988. [CrossRef]

15. Park S, Hwang Y, Lee HJ, Park IK, Kim YT, Kang CH. Compar- ison of robot-assisted esophagectomy and thoracoscopic esophagectomy in esophageal squamous cell carcinoma. J Thorac Dis 2016;8:2853-61. [CrossRef]

16. Suda K, Ishida $Y$, Kawamura $Y$, Inaba K, Kanaya S, Teramukai $\mathrm{S}$, et al. Robot-assisted thoracoscopic lymphadenectomy along the left recurrent laryngeal nerve for esophageal squamous cell carcinoma in the prone position: technical report and short-term outcomes. World J Surg 2012;36:1608-16.

17. He H, Wu Q, Wang Z, Zhang Y, Chen N, Fu J, et al. Short-term outcomes of robot-assisted minimally invasive esophagectomy for esophageal cancer: a propensity score matched analysis. J Cardiothorac Surg 2018;13:52. [CrossRef]

18. van der Sluis $P C$, van der Horst S, May AM, Schippers $C$, Brosens LA, Joore HCA, et al. Robot-assisted Minimally Invasive Thoracolaparoscopic Esophagectomy Versus Open Transthoracic Esophagectomy for Resectable Esophageal Cancer: A Randomized Controlled Trial. Ann Surg. 2019;269:621-30. [CrossRef]

19. Osugi H, Takemura M, Higashino M, Takada N, Lee S, Kinoshita $\mathrm{H}$. A comparison of video-assisted thoracoscopic oesophagectomy and radical lymph node dissection for squamous cell cancer of the oesophagus with open operation. Br J Surg 2003;90:108-13. [CrossRef]

20. Smithers BM, Gotley DC, Martin I, Thomas JM. Comparison of the outcomes between open and minimally invasive esophagectomy. Ann Surg 2007;245:232-40. [CrossRef]

21. Dantoc M, Cox MR, Eslick GD. Evidence to support the use of minimally invasive esophagectomy for esophageal cancer: a meta-analysis. Arch Surg 2012;147:768-76. [CrossRef]

22. Markar SR, Wiggins T, Antonowicz S, Zacharakis E, Hanna GB. Minimally invasive esophagectomy: Lateral decubitus vs. prone positioning; systematic review and pooled analysis. Surg Oncol 2015;24:212-9. [CrossRef]

23. Miyata $H$, Sugimura $K$, Yamasaki M, Makino T, Tanaka $K$, Morii E, et al. Clinical impact of the location of lymph node metastases after neoadjuvant chemotherapy for middle and lower thoracic esophageal cancer. Ann Surg Oncol 2019;26:200-8.

24. Fujiwara $H$, Shiozaki A, Konishi $H$, Otsuji E. Mediastinoscope and laparoscope-assisted esophagectomy. J Vis Surg 2016;2:125. [CrossRef]

25. Fujiwara $H$, Shiozaki $A$, Konishi $H$, et al. Single-Port Mediastinoscopic Lymphadenectomy Along the Left Recurrent Laryngeal Nerve. Ann Thorac Surg 2015;100:1115-7. [CrossRef]

26. Chao Y-K, Hsieh M-J, Liu Y-H, Liu H-P. Lymph Node Evaluation in Robot-Assisted Versus Video-Assisted Thoracoscopic Esophagectomy for Esophageal Squamous Cell Carcinoma: A Propensity-Matched Analysis. World J Surg 2018;42:590-8. [CrossRef]

27. Wullstein $\mathrm{C}$, Ro-Papanikolaou $\mathrm{H}-\mathrm{Y}$, Klingebiel $\mathrm{C}$, Ersahin $\mathrm{K}$, Carolus R. Minimally invasive techniques and hybrid operations for esophageal cancer. Viszeralmedizin 2015;31:3316. [CrossRef]

28. van Hillegersberg R, Seesing MFJ, Brenkman HJF, Ruurda JP. Robot-assisted minimally invasive esophagectomy. Chirurg 2017;88:7-11. [CrossRef] 
29. Xiong W-L, Li R, Lei H-K, Jiang Z-Y. Comparison of outcomes between minimally invasive oesophagectomy and open oesophagectomy for oesophageal cancer. ANZ J Surg 2017;87:165-70. [CrossRef]

30. Nagpal K, Ahmed K, Vats A, Yakoub D, James D, Ashrafian H, et al. Is minimally invasive surgery beneficial in the management of esophageal cancer? A meta-analysis. Surg Endosc 2010;24:1621-9. [CrossRef]

31. Guo W, Ma X, Yang S, Zhu X, Qin W, Xiang J, et al. Combined thoracoscopic-laparoscopic esophagectomy versus open esophagectomy: a meta-analysis of outcomes. Surg Endosc 2016;30:3873-81. [CrossRef]

32. Lv L, Hu W, Ren Y, Wei X. Minimally invasive esophagectomy versus open esophagectomy for esophageal cancer: a metaanalysis. Onco Targets Ther 2016;9:6751-62. [CrossRef]

33. Maas KW, Biere SSAY, Scheepers JJG, Gistbertz SS, Rordigues VTT, van der Peet DL, et al. Minimally invasive intrathoracic anastomosis after Ivor Lewis esophagectomy for cancer: a review of transoral or transthoracic use of staplers. Surg Endosc 2012;26:1795-802. [CrossRef]
34. Takeuchi $\mathrm{H}$, Kawakubo $\mathrm{H}$, Kitagawa $\mathrm{Y}$. Current status of minimally invasive esophagectomy for patients with esophageal cancer. Gen Thorac Cardiovasc Surg 2013;61:513-21. [CrossRef]

35. van der Sluis PC, Ruurda JP, Verhage RJJ, van der Host $S$, Haverkamp L, Siersema PD, et al. Oncologic Long-Term Results of Robot-Assisted Minimally Invasive Thoraco-Laparoscopic Esophagectomy with Two-Field Lymphadenectomy for Esophageal Cancer. Ann Surg Oncol 2015;22 Suppl 3:S1350-6. [CrossRef]

36. Tagkalos E, Goense L, Hoppe-Lotichius M, Ruurda JP, Babic B, Kneist W, et al. Robot-assisted minimally invasive esophagectomy (RAMIE) compared to conventional minimally invasive esophagectomy (MIE) for esophageal cancer: a propensitymatched analysis. Dis Esophagus 2019. [CrossRef]

37. Park SY, Kim DJ, Do YW, Suh J, Lee S. The Oncologic Outcome of Esophageal Squamous Cell Carcinoma Patients After Robot-Assisted Thoracoscopic Esophagectomy With Total Mediastinal Lymphadenectomy. Ann Thorac Surg 2017; 103:1151-7. [CrossRef] 